\title{
Pembuatan Aplikasi Dokumentasi Jaringan
}

\author{
Albert Briliakta G.S. ${ }^{1}$ \\ albert.briliakta@gmail.com
}

\author{
Nugroho Agus H. ${ }^{2}$ \\ cnuq@ukdw.ac.id
}

\author{
Joko Purwadi ${ }^{3}$ \\ jpurwadi@yahoo.com
}

\begin{abstract}
Company networks are continually expanding to meet the needs of the company. Therefore the company must add or even change the structure of the network or network topology. In this case a network administrator must also change the network documentation in accordance with the development, The documentation contains information from every device on the network. Topology changes can be difficult for network administrators in managing the network if it does not have good documentation. The application built by the author proved helpful in making the network documentation. It provide and assist network administrators in making the topology and document in the printed form that can be used as documentation of the network by the company. So it can help network administrators manage and maximize the network.
\end{abstract}

Kata kunci : Network Documentation.

\section{PENDAHULUAN}

Dokumentasi jaringan adalah blueprint yang berisi semua informasi mengenai jaringan yang dirangkum menjadi sebuah dokumen. Dokumen tersebut berisi detail dari informasi mengenai hardware, software licence, konfigurasi sebuah desktop, prosedur backup, dan lain-lain. Dokumentasi jaringan menjadi hal yang wajib untuk dibuat dalam sebuah instansi yang menggunakan jaringan untuk operasionalnya. Dokumentasi jaringan berisikan semua informasi mengenai configurasi yang terdapat pada jaringan instansi tersebut, dokumentasi dapat membantu seorang administrator jaringan untuk perawatan maupun meningkatkan performa jaringan dengan merubah beberapa bagian topologi.

Permasalahan yang muncul adalah saat seorang administrator jaringan mendokumentasikan jaringan, tools yang tersedia hanya sebatas pembuatan topologi jaringan. Saat ini hanya terdapat

\footnotetext{
${ }^{1}$ Teknik Informatika, Fakultas Teknologi Informasi, Universitas Kristen Duta Wacana, Yogyakarta

${ }^{2}$ Teknik Informatika, Fakultas Teknologi Informasi, Universitas Kristen Duta Wacana, Yogyakarta

${ }^{3}$ Teknik Informatika, Fakultas Teknologi Informasi, Universitas Kristen Duta Wacana, Yogyakarta
} 
tools untuk menggambarkan sebuah topologi jaringan, seperti Microsoft Visio 2011 atau software simulasi jaringan seperti Packet Tracer milik Cisco. Seorang administrator jaringan harus membuat dokumentasi secara manual berdasarkan topologi yang telah dibuat sebelumnya. Permasalahan yang muncul adalah tidak semua administrator jaringan memiliki kemampuan untuk membuat dokumentasi yang baik mengenai jaringan pada instansi tersebut, sehingga terkadang informasi yang tercatat pada sebuah dokumentasi jaringan tidak menyangkup semua hal pada jaringan tersebut.

\section{LANDASAN TEORI}

\subsection{Dokumentasi Jaringan}

Menurut David Goldschmidt (2005) pengertian dokumentasi jaringan adalah blueprint yang berisi semua informasi mengenai jaringan yang dirangkum menjadi sebuah dokumen. Dokumen tersebut berisi detail dari informasi mengenai hardware, software licence, konfigurasi sebuah desktop, prosedur backup, dan lain-lain. tetapi tidak ada ketentuan secara pasti mengenai apa saja yang harus dicantumkan pada sebuah dokumentasi jaringan.

Dokumentasi jaringan memiliki 10 langkah yang dapat dilakukan untuk membuat sebuah dokumentasi jaringan yang baik (Posey.B, 2008, 1), langkah-langkahnya adalah sebagai berikut :

1. Membuat network documentation policy.

2. Membuat diagram topologi jaringan.

3. Dokumentasi nama server, aturan dan alamat IP

4. Membuat change log untuk masing-masing server

5. Dokumentasi versi dari software dan juga bukti keaslian software

6. Dokumentasi komponen hardware

7. Dokumentasi active directory

8. Dokumentasi backup procedure

9. Memberi Label

10. Evaluasi Dokumentasi Jaringan

Langkah-langkah diatas adalah proses jalannya dokumentasi jaringan. Beberapa aspek telah dicantumkan diatas untuk dokumentasi jaringan, selain aspek-aspek diatas sebuah dokumentasi jaringan harus memiliki komponen sebagai berikut : 


\subsubsection{NetworkTtopology Diagram}

Diagram topologi jaringan adalah sebuah representasi grafis dari sebuah jaringan yang menggambarkan bagaimana setiap device di dalam jaringan terhubung satu dengan yang lain dan juga secara logical architecture (Graziani.R \& Vachon.B, 2008, 527). Sebuah diagram topologi jaringan juga memiliki beberapa hal yang harus tercantum yaitu:

- Semua symbol jaringan dan bagaimana mereka terhubung.

- Tipe interface, nomor, alamat IP dan subnet mask.

- Protokol WAN.

Topologi Jaringan memuat hal-hal yang telah dijelaskan diatas seperti beberapa jenis device jaringan, koneksinya antar device, alamat IP, nomer interface dan lain-lain.

\subsubsection{Tabel Konfigurasi Jaringan}

Tabel konfigurasi jaringan adalah sebuah tabel yang berisi data-data mengenai hardware dan software pada sebuah jaringan secara up-to-date. Tabel ini berisi informasi-informasi penting yang dapat membantu seorang network administrator untuk mencari kesalahan dalam sebuah jaringan (Graziani.R \&Vachon.B, 2008, 528).

Tabel konfigurasi jaringan memuat konfigurasi router yang terdapat pada sebuah jaringan, berisikan beberapa informasi yang dibutuhkan seperti nama interfacenya, mac address, IP address beserta routingnya.

Tabel konfigurasi jaringan terdapat informasi mengenai switch yang terdapat pada sebuah jaringan, informasi tersebut meliputi nama hostname, port, speed, duplex, Spanning tree protocol, port fast, trunk status, ether channel yang menunjukkan interface tersebut bekerja pada pada layer berapa, kemudian ada vlan (virtual network) dan juga key yang menunjukkan keterangan penting untuk interface tersebut.

\subsubsection{Tabel Konfigurasi Perangkat Jaringan Ahkir}

Tabel konfigurasi perangkat jaringan ahkir berisikan catatan mengenai dasar dari hardware dan software yang digunakan pada setiap perangkat yang terbubung ke jaringan termasuk server, management console dan desktop workstation (Graziani.R \&Vachon.B, 2008, 531).

Tabel konfigurasi perangkat jaringan ahkir berisikan informasi mengenai end-system configuration tiap-tiap PC atau server yang terhubung pada jaringan. informasi tersebut melingkupi device name, jenis dan seri dari OS (Operating System), alamat IP, subnet mask, default gateway, 
DNS server, WINS server, dan juga semua software yang berjalan pada device tersebut yang memerlukan bandwidth besar.

\subsubsection{Network baseline}

Network baseline adalah sebuah dokumen yang berisikan catatan mengenai performa jaringan pada kondisi normal. Network baseline ini berguna saat terjadi beberapa kendala pada performa jaringan, maka seorang network administrator dapat menbandingkan permasalahan yang dihadapi dengan network baseline yang telah dicatat sebelumnya sehingga dapat mempermudah penyelesaian masalah.

\subsection{Visualisasi}

Definisi software visualization adalah suatu disiplin ilmu yang menggunakan berbagai bentuk citra untuk memberikan wawasan dan pemahaman serta untuk mengurangi kompleksitas sistem perangkat lunak yang ada. Pemahaman yang selanjutnya mengenai software visualization adalah proses penggambaran sebuah entitas dalam sistem domain kedalam penggambaran secara grafis untuk membantu pemahaman dan pengembangan

\section{HASIL DAN PEMBAHASAN}

Penulis membuat sebuah program untuk memberikan solusi permasalahan yang muncul sebelumnya. Berikut pembahasan mengenai beberapa bagian yang mengolah input data dari pengguna pada beberapa langkah program.

Bagian input author disajikan saat pertama kali program dijalankan. Memunculkan box yang berisi informasi author dan juga lokasi dokumentasi jaringan. Pengguna dapat memasukkan parameter berupa text pada textinput masing-masing bagian. Mulai dari name author, lokasi gedung, lantai, hingga ruangan.

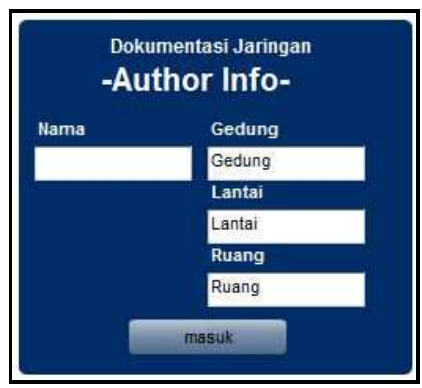

Gambar 1. Form Author 
Proses Menarik dan Meletakkan Perangkat Jaringan memiliki beberapa tahapan. Pertama saat perangkat jaringan yang dibutuhkan dipilih, kedua saat perangkat jaringan ditarik, dan terahkir saat perangkat jaringan diletakkan pada canvas, potongan program terdapat pada fungsi Menarik dan Meletakkan Perangkat Jaringan masing-masing perangkat jaringan. Pada waktu dilepas program akan melihat posisi perangkat jaringan. Program akan melihat erangkat jaringan tersebut terletak didalam canvas atau tidak. Saat perangkat jaringan tersebut terletak diluar canvas, maka object tersebut akan dihilangkan dari media penyimpanan array sebelumnya dan akan dihapus dari canvas. Bila perangkat jaringan tersebut masuk ke area canvas, maka perangkat jaringan tersebut tetap akan dimasukkan kedalam canvas sesuai koordinat terahkir kali object perangkat jaringan tersebut dipindahkan. Gambar 2 menunjukkan pembuatan topologi jaringan dengan menarik dan meletakkand device.

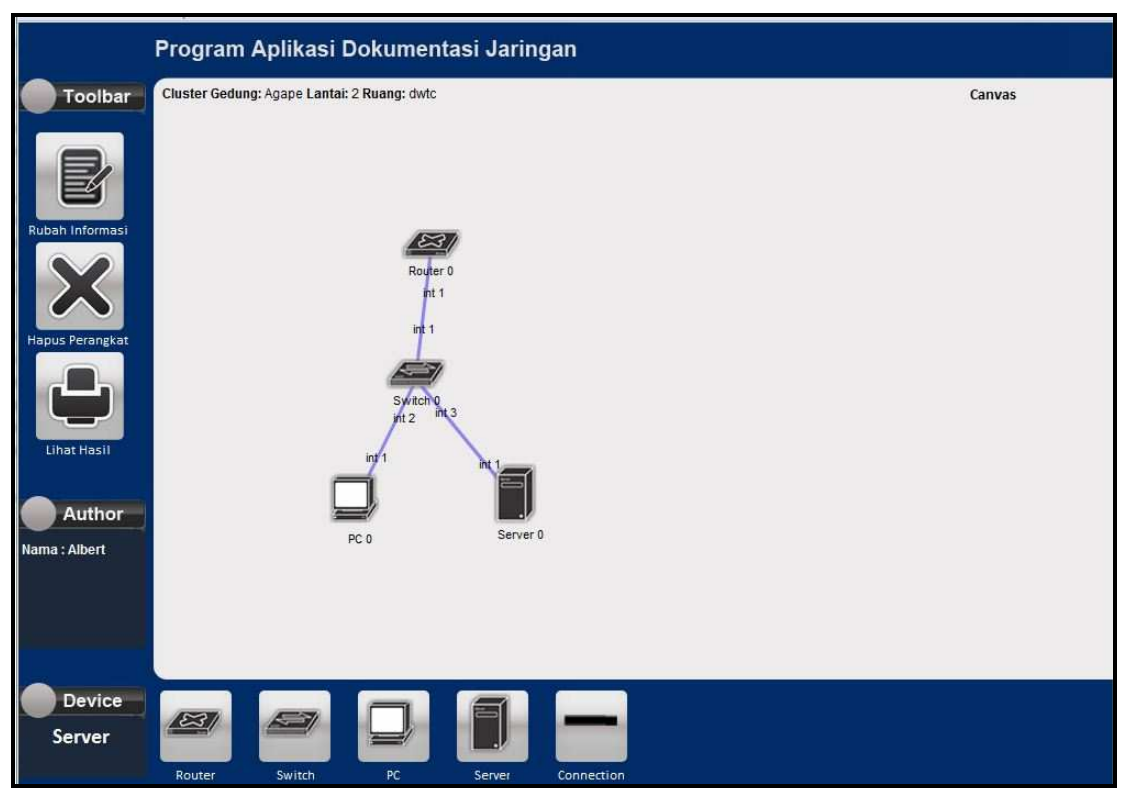

Gambar 2. Proses Pembuatan Topologi dengan Menarik dan Meletakkan Device

Fungsi akan menampilkan sebuah jendela untuk mengubah informasi perangkat jaringan tersebut sewaktu dipilih duakali atau dipilih menggunakan alat untuk merubah informasi perangkat yang terdapat pada toolbar. Pada bagian program ini sama seperti jendela author sebelumnya, menggunakan TextInput yang akan menerima inputan dari keyboard user ke dalam program. sistem memasukkan tampungan sementara dari info yang telah dirubah pada perangkat jaringan sebelumnya. Informasi yang terdapat di tampungan object dalam contoh diatas adalah perangkat 
jaringan router diperbaharui dengan tampText yang menampung hasil perubahan informasi pada proses sebelumnya.

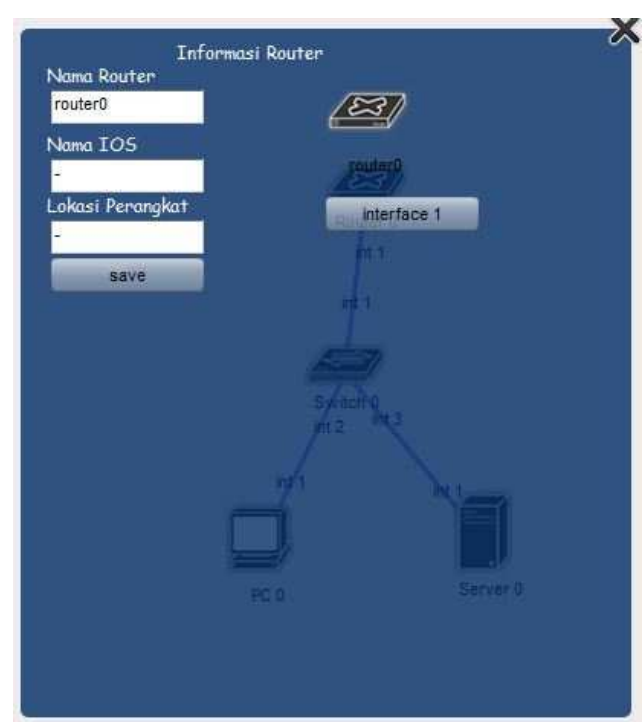

Gambar 3. Rubah informasi device

Gambar 3 menunjukkan device Router yang akan dirubah informasi awal sesuai dengan kebutuhan user.

Pada proses melihat dokumentasi jaringan, pengguna dapat melihat hasil dokumentasi jaringan dengan cara menggunakan tombol lihat hasil yang terletak pada bagian tool bar program.

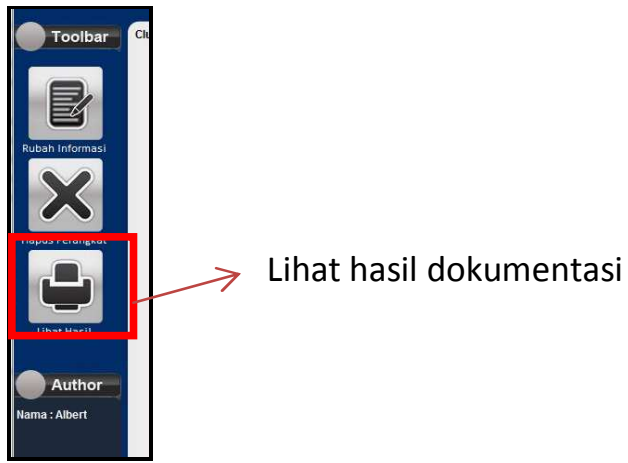

Gambar 4. Icon lihat hasil dokumentasi

Hasil keluaran dari dokumentasi jaringan yang dibuat akan seperti pada gambar 5 berikut ini: 


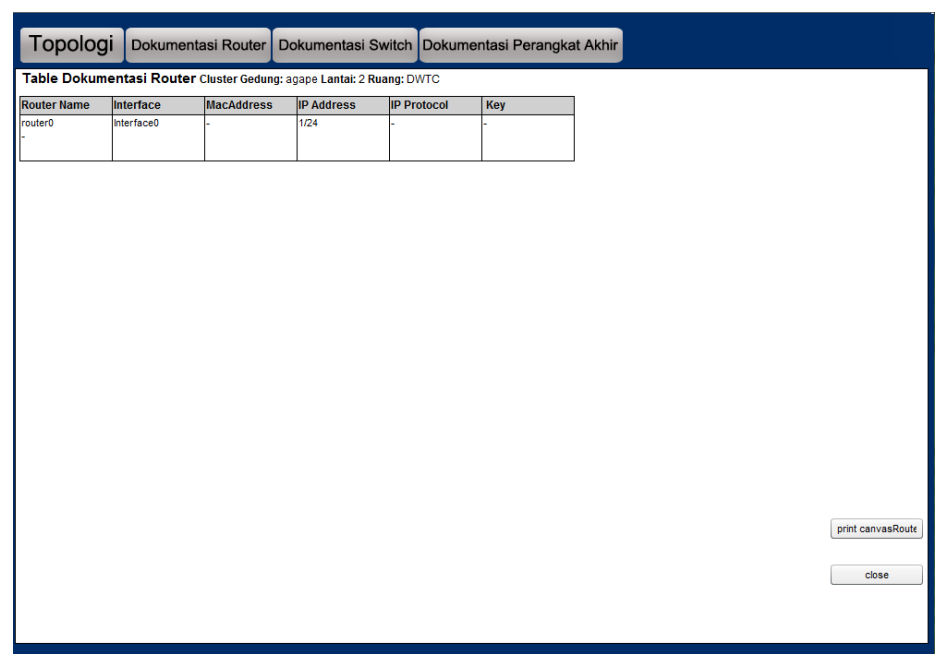

Gambar 5. Tampilan Dokumentasi Router

Pada gambar 5 diperlihatkan sebuah dokumentasi router yang memiliki informasi seputar router yang dibuat pada topologi sebelumnya, informasi tersebut berisi seputar nama router, lokasi router, seri dan IOS router, dan juga interface yang terdapat pada router. Seperti alamat $I P$, protocol dan key dari interface tersebut. Dokumentasi ini mencakup 4 bagian yaitu topologi, dokumentasi router, switch, dan perangkat akhir.

Pengujian sistem ini dilakukan penulis dengan sample sebanyak 30 responden dengan memberikan beberapa pertanyaan seputar dengan desain dan fungsionalitas program. Hasil dari kuisioner tersebut tercantum dalam tabel 1 berikut:

Tabel 1.

Tabel Nilai Tingkat Kepuasan Pengguna Terhadap Desain

\begin{tabular}{|c|c|c|c|c|c|}
\hline \multicolumn{3}{|c|}{ parameter yang diteliti } & \multicolumn{2}{|c|}{ hasil kuisioner } & \multirow[b]{2}{*}{ nilai } \\
\hline \multicolumn{2}{|r|}{ bagian 3} & & M (nilai 5) & TM (nilai 1) & \\
\hline $\mathrm{A}$ & layout program secara keseluruhan & 1 & 26 & 4 & 4,47 \\
\hline \multirow[t]{6}{*}{$\mathrm{B}$} & tata letak beberapa bagian program & & & & \\
\hline & tata letak tool bar & 2 & \multicolumn{3}{|c|}{3,83} \\
\hline & tata letak device bar & 4 & \multicolumn{3}{|c|}{4,00} \\
\hline & tata letak window edit properti & 6 & \multicolumn{3}{|c|}{3,77} \\
\hline & tata letak window show print & 8 & \multicolumn{3}{|c|}{3,93} \\
\hline & & & \multicolumn{2}{|c|}{ total nilai } & 3,88 \\
\hline
\end{tabular}


Tabel 1. (lanjutan)

Tabel Nilai Tingkat Kepuasan Pengguna Terhadap Desain

\begin{tabular}{|c|c|c|c|c|c|}
\hline $\mathrm{C}$ & desain beberapa bagian program & & & & \\
\hline & desain tool bar & 3 & \multicolumn{3}{|c|}{3,63} \\
\hline & desain device bar & 5 & \multicolumn{3}{|c|}{3,57} \\
\hline & desain windows edit properti & 7 & \multicolumn{3}{|c|}{3,73} \\
\hline & desain window show print & 9 & \multicolumn{3}{|c|}{3,67} \\
\hline & & & \multicolumn{2}{|c|}{ total nilai } & 3,65 \\
\hline \multirow[t]{4}{*}{$\mathrm{D}$} & apakah ukuran icon sudah sesuai & & ya (5) & tidak (1) & \\
\hline & icon tool bar & 10 & 20 & 10 & 3,67 \\
\hline & icon device bar & 11 & 22 & 8 & 3,93 \\
\hline & & & \multicolumn{2}{|c|}{ total nilai } & 3,80 \\
\hline $\mathrm{E}$ & $\begin{array}{l}\text { icon sudah merepresentasikan device jaringan } \\
\text { pada device bar }\end{array}$ & 12 & 26 & 0 & 5 \\
\hline \multicolumn{5}{|c|}{ total nilai bagian desain program } & 4,16 \\
\hline
\end{tabular}

Tabel 2.

Nilai Tingkat Kepuasan Pengguna Terhadap Fungsionalitas

\begin{tabular}{|c|c|c|c|c|c|}
\hline \multicolumn{2}{|r|}{ bagian 4} & & \multirow{2}{*}{$\begin{array}{c}\text { ya (5) } \\
15\end{array}$} & \multirow{2}{*}{$\frac{\operatorname{tidak}(\mathbf{1})}{15}$} & \multirow[b]{2}{*}{3} \\
\hline A & kemudahaan penggunaan program & 1 & & & \\
\hline & & & tidak (5) & ya (1) & \\
\hline \multirow[t]{2}{*}{ B } & fungsi drag and drop mempersulit atau tidak & 2 & 25 & 5 & 4,33 \\
\hline & & & ya (5) & tidak (1) & \\
\hline \multirow[t]{2}{*}{$\mathrm{C}$} & memahami kegunaan tool bar saat menggunakan program & 3 & 19 & 11 & 3,53 \\
\hline & & & mudah (5) & sulit (1) & \\
\hline \multirow[t]{5}{*}{$\mathrm{D}$} & \multicolumn{2}{|l|}{ penggunaan beberapa tool pada tools bar } & & & \\
\hline & edit & 4 & 21 & 9 & 3,80 \\
\hline & delete & 5 & 24 & 6 & 4,20 \\
\hline & show print & 6 & 28 & 2 & 4,73 \\
\hline & & & total & ilai & 4,24 \\
\hline $\mathrm{E}$ & $\begin{array}{l}\text { informasi yang dapat dirubah pada sebuah device atau } \\
\text { interface }\end{array}$ & & ya (5) & tidak (1) & \\
\hline & device router & 7 & 28 & 2 & 4,73 \\
\hline
\end{tabular}


Tabel 2. (lanjutan)

Nilai Tingkat Kepuasan Pengguna Terhadap Fungsionalitas

\begin{tabular}{|c|c|c|c|c|c|}
\hline & interface router & 8 & 27 & 3 & 4,60 \\
\hline & device switch & 9 & 27 & 3 & 4,60 \\
\hline & interface switch & 10 & 30 & 0 & 5,00 \\
\hline & device end user & 11 & 28 & 2 & 4,73 \\
\hline & interface end user & 12 & 30 & 0 & 5,00 \\
\hline & & & \multicolumn{2}{|c|}{ total nilai } & 4,78 \\
\hline \multirow[t]{6}{*}{$\mathrm{F}$} & informasi yang dicantumkan pada tabel dokumentasi & & M (5) & TM (1) & \\
\hline & router & 13 & 26 & 4 & 4,47 \\
\hline & switch & 14 & 28 & 2 & 4,73 \\
\hline & end device & 15 & 29 & 1 & 4,87 \\
\hline & & & \multicolumn{2}{|c|}{ total nilai } & 4,69 \\
\hline & & & tidak (5) & ya (1) & \\
\hline \multirow[t]{2}{*}{$\mathrm{G}$} & proses mencetak dokumentasi jaringan & 16 & 24 & 6 & 4,20 \\
\hline & & & ya (5) & tidak (1) & \\
\hline $\mathrm{H}$ & $\begin{array}{l}\text { adanya program dokumentasi jaringan memudahkan } \\
\text { pendokumentasian jaringan }\end{array}$ & 17 & 30 & 0 & 5 \\
\hline \multicolumn{5}{|c|}{ total nilai bagian fungsionalitas program } & 4,23 \\
\hline
\end{tabular}

Dari penelitian yang telah dilakukan menggunakan kuisoner, ditentukan titik kepuatas pengguna sebesar 3,7 yaitu $74 \%$ dari 5 (nilai maksimal). Pertanyaan utama adalah pertanyaan nomer 17 yang berisikan mengenai apakah program dokumentasi jaringan ini membantu dalam proses dokumentasi jaringan. dengan 30 orang responden yang mengisi, 30 orang menjawab "ya" yang menunjukkan program ini membantu dalam proses dokumentasi jaringan. walaupun tujuan utama penelitian sudah terpenuhi tetapi program tetap diperbaiki menurut komentar yang diberikan oleh para responden.

Total nilai dari desain dan fungsionalitas program berdasarkan kuisioner sudah menunjukkan nilai diatas titik batas kepuasan program yaitu untuk desain adalah 4,01 dan untuk fungsionalitas program 4,23 . Nilai tersebut menggambarkan nilai dari kedua parameter utama telah melebihi titik kepuasan yang ditentukan dalam penelitian ini. Tetapi kemudian pada masing-masing parameter utama muncul beberapa pertanyaan yang memiliki nilai dibawah 3,7, sehingga berdasarkan pertanyaan-pertanyaan yang nilainya tidak memenuhi tersebut dilakukan perbaikan 
terhadap program dokumentasi jaringan. perbaikan diperlukan untuk meningkatkan tingkat kepuasan pengguna terhadap beberapa point tersebut.

Dari hasil kuisioner tersebut dilakukan perbaikan desain dan fungsionalitas program kemudian diberikan lagi ke responden. Berikut ini hasil perbandingan nilai dari nilai kuisioner pertama dan tahap kedua.

Tabel 3.

Nilai Kepuasan 10 Orang Contoh Terhadap 5 Pertanyaan pada tahap 1

\begin{tabular}{|c|l|c|}
\hline No & Pertanyaan & nilai \\
\hline 1 & Mengenai desain toolbar & 3,3 \\
\hline 2 & Mengenai desain perangkat jaringan bar & 3,3 \\
\hline 3 & Mengenai desain jendela untuk melihat dokumentasi & 3,5 \\
\hline 4 & Mengenai kemudahan penggunaan program & 2,6 \\
\hline 5 & Mengenai kegunaan toolbar saat program dijalankan & 3 \\
\hline
\end{tabular}

Tabel 4.

Nilai Kepuasan 10 Orang Contoh Terhadap 5 Pertanyaan pada tahap 2

\begin{tabular}{|c|l|c|}
\hline No & Pertanyaan & nilai \\
\hline 1 & Mengenai desain toolbar & 3,8 \\
\hline 2 & Mengenai desain perangkat jaringan bar & 3,6 \\
\hline 3 & Mengenai desain jendela untuk melihat dokumentasi & 3,7 \\
\hline 4 & Mengenai kemudahan penggunaan program & 3,4 \\
\hline 5 & Mengenai kegunaan toolbar saat program dijalankan & 5 \\
\hline
\end{tabular}

Table 3 dan 4 menunjukkan nilai dari 5 pertanyaan yang berada dibawah batas kepuasan yang ditentukan penulis, pada kedua table tersebut tercantum nilai dari 5 pertanyaan dari 10 responden yang dipilih secara acak. Hasil dari kedua tabel diatas menunjukkan kenaikan nilai kepuasan pengguna dari masing-masing pertanyaan yang diujikan kembali. Dari hasil akhir yang didapat masih terdapat beberapa pertanyaan yang belum mencapai titik kepuasan pengguna sebesar 3.7 yaitu pertanyaan mengenai desain perangkat jaringan dan juga kemudahan penggunaan program. 


\section{KESIMPULAN DAN SARAN}

Berdasarkan hasil implementasi dan analisis sistem, maka diperoleh kesimpulan sebagai berikut :

a) Nilai kepuasan pengguna pada bagian desain program sebesar 4,16 telah memenuhi tingkat kepuasan yang ditentukan yaitu 3,7 .

b) Nilai kepuasan pengguna pada bagian fungsionalitas program sebesar 4,23 telah memenuhi tingkat kepuasan sebesar 3,7.

c) Nilai kepuasan pengguna terhadap 5 permasalahan yang diangkat pada tahap 2 telah naik 0,76 dari nilai awal 3,14 dan nilai ahkir sebesar 3,90.

d) Perubahan program pada tahap kedua kuisioner telah meningkatkan nilai kepuasan pengguna terhadap permasalahan yang memiliki nilai dibawah 3,7.

e) Menurut penelitian tahap pertama program aplikasi dokumentasi jaringan membantu pengguna dalam membuat dokumentasi jaringan pada sebuah topologi.

Saran yang diajukan oleh penulis untuk pengembangan sistem demi mencapai hasil yang lebih baik adalah:

a) Program dikembangkan agar dapat menampung lebih banyak device.

b) Keterbatasan pada tabel dokumentasi diperbaharui sehingga dapat menampung lebih banyak dokumetasi perangkat jaringan.

c) Pengembangan program berikutnya menambahkan beberapa golongan baru device seperti router wireless, access point, dan lain-lain.

\section{Daftar Pustaka}

Babu D., Govindarajulu P., Renddy R., Kumari A. (2009). A Heuristic Approach for Selection of Software Architecture Using Functional Key Areas and Visualization Tools Integrated with Darch. Diakses 18 september 2011 dari http://paper.ijcsns.org/07_book/200906/20090636.pdf

Goldschmidt D. (2005). network documentation - A cornerstone for disaster recovery. Diakses pada 20 oktober 2011 dari http://www.techrepublic.com/whitepapers/network-documentation-a-cornerstone-for-disaster-recovery/244877

Miller D. (2006). Why Network Documentation is so Important. Diakses pada tanggal 20 Oktober 2011 dari http://www.networkdocumentation.com/index2.php?option=com content\&do $\mathrm{pdf}=1 \& \mathrm{id}=18$

Moravek P., Jelinek M., Komosny D., dan Simek M. (2008). Visualization of a Hierarchical Aggregation in the IPTV Network Environment. Diakses 18 september 2011 dari http://paper.ijcsns.org/07 book/200811/20081149.pdf

Posey B. (2008). Channel Checklist: 10 Steps for Network Documentation. Diakses pada tanggal 1 oktober 2011 dari http://searchnetworkingchannel.bitpipe.com/rlist/term/Networking.html

Vachon B., Graziani R. (2008) Accessing the WAN :CCNA exploration companion guide. Indianapolis : Cisco Press. 